\title{
Role of temperature, seedling-age and soil moisture on collar rot disease in lentil caused by Sclerotium rolfsii and identification of resistance sources
}

\section{Anirban Roy}

BCKV: Bidhan Chandra Krishi Viswa Vidyalaya

\section{Camellia Das}

BCKV: Bidhan Chandra Krishi Viswa Vidyalaya

\section{Diana Sagolsem}

BCKV: Bidhan Chandra Krishi Viswa Vidyalaya

\section{Dhriti Ghose}

Visva-Bharati

\section{Sumit K Murmu}

BCKV: Bidhan Chandra Krishi Viswa Vidyalaya

Moutushi Sarkar

BCKV: Bidhan Chandra Krishi Viswa Vidyalaya

\section{Birendra Nath Panja}

BCKV: Bidhan Chandra Krishi Viswa Vidyalaya

\section{Rajib Nath}

BCKV: Bidhan Chandra Krishi Viswa Vidyalaya

Kuldeep Tripathi

BCKV: Bidhan Chandra Krishi Viswa Vidyalaya

Prabir K Bhattacharyya

BCKV: Bidhan Chandra Krishi Viswa Vidyalaya

Somnath Bhattacharyya ( $\square$ somnathbhat@yahoo.com )

BCKV: Bidhan Chandra Krishi Viswa Vidyalaya https://orcid.org/0000-0002-9261-6931

\section{Research Article}

Keywords: Sclerotium rolfsii, Soil-moisture, Seedling-age, Mycelial-load, Resistance source

Posted Date: August 23rd, 2021

DOI: https://doi.org/10.21203/rs.3.rs-836690/v1 
License: (c) (i) This work is licensed under a Creative Commons Attribution 4.0 International License. Read Full License 


\section{Abstract}

Collar rot disease caused by Sclerotium rolfsii attacks lentils at the seedling stage and reduces plant population considerably in the field. Although soil moisture and temperature influence disease development much, no concrete attempts to find the optimum level of moisture, temperature, and seedling age have been made in lentils. Here, we identified optimum soil moisture, temperature, and seedling age that allow successful infection by $S$. rolfsii and maximum seedling mortality in a controlled environment inside a plant growth chamber. Screening of one hundred and ninety genotypes for two consecutive years in the field identified some resistant genotypes. Ten genotypes were selected from earlier screening and further evaluated in sick plots at two different locations with different $\mathrm{pH}$ for three consecutive years. About $80 \%$ variation in disease resistance was due to genotypes, and minor infection of collar rot disease was observed in acidic lateritic soil than in neutral alluvial soil. Furthermore, low mycelial load in a selected resistant genotype was confirmed by quantitative real-time PCR using an $S$. rolfsii specific primer pair. The identified resistant genotypes will be helpful to breeding collar rot resistant cultivars and mapping disease resistance. In addition, the study improves the understanding of the development of collar rot disease, which is critical for expanding the area under cultivation in Asia, especially in rice fallows.

\section{Introduction}

Lentil (Lens culinaris Medik.) is a self-pollinating, annual cool-season legume cultivated widely for its high protein content. It ranks third among all grain legume areas next to chickpeas (Cicer arietinum $\mathrm{L}$.) and peas (Pisum sativum L.). It is rich in carbohydrates, vitamin B, minerals, lysine, and tryptophan amino acids (Malhotra et al., 2018). It is rich in prebiotic carbohydrates also (Johnson et al. 2020). Globally, lentil is grown in $6.1 \mathrm{Mha}$ of land with annual production and productivity of $6.3 \mathrm{Mt}$ and $1038 \mathrm{~kg}$ $\mathrm{h}^{-1}$ (Choukri et al. 2020). India is the second-largest producer of lentils after Canada, with $3.61 \mathrm{Mt}$ and 0.87 Mt annual productions, respectively.

Lentil is generally grown in soils with residual moisture from the preceding wet season rice crop. Several soil-borne fungi, like Sclerotium, Rhizoctonia, attack lentils at the early growth stage resulting in seedling mortality in the field. Collar rot disease caused by Sclerotium rolfsii is a significant disease of lentil seedlings that may drastically reduce population stand in the area. The disease also hinders efforts to expand the land under lentil cultivation in rice fallow, especially in India (Tarafder et al., 2018). This disease is also prevalent in several lentil growing countries like China, Pakistan, Nepal, and Bangladesh and also infects other legumes such as chickpea and groundnut (Bera et al. 2016; Dodia et al. 2019). The disease manifests water-soaked symptoms on stems, and finally, rotting of seedling stem occurs. The pathogen is soil-borne, highly polyphagous, moisture-loving, sclerotia, and ubiquitous facultative basidiomycetes fungus. It produces oxalic acid, polygalacturonase, and cellulase as pathogenic weapons to establish infection. In the off-season, the pathogen survives in the soil as Sclerotium, which serves as the primary source of inoculum for disease development (Chet 1975; Pravi et al. 2014). It 
attacks the plants above the soil level, causing stem rot, resulting in seedlings toppling. Sclerotium rolfsii attacks more than 200 species of plants, including some species of weeds (Cui et al. 2020).

Epidemiological studies of collar rot caused by Sclerotium rolfsii are limited even though some information on pathogen survival and biology of sclerotia are available (Chet 1975; Punja et al. 1984; Pravi et al. 2014). Although it is known that the Sclerotium pathogen flourishes in moist soils, how various soil moisture regimes may affect its survival is unknown. In rice fallow areas, where lentil is mainly grown in large regions of the Indian subcontinent, soil moisture and temperature vary considerably with time (days after harvest of the preceding rice crop) and area. Variable incidence of the disease is generally observed based on soil moisture content, temperature, and seedling age. However, there is no concrete information available on how these environmental factors may contribute to disease development. The incidence of collar rot is generally less in late sown crops (sown in the first week of December in a part of Eastern India), but late sowing exposes the crop to terminal heat stress. On the contrary, no concrete attempts were initiated to identify collar rot-resistant genotypes despite ample germplasm resources in lentils. Identification of resistance sources may be the significant first step in breeding collar rot-resistant lentil cultivars and genetic mapping of resistance.

Here, we screened one hundred and ninety genotypes of lentils against the collar rot pathogen $S$. rolfsii under artificial inoculation and in sick plots in the field and identified resistant genotypes. Furthermore, the low mycelial load of the pathogen in resistant genotype was confirmed using quantitative real-time PCR. The study elucidated the optimum soil moisture, temperature, and seedling age on maximum disease development by Sclerotium rolfsii. The identified resistant genotypes will be helpful in breeding collar rot-resistant cultivars and mapping disease resistance. In addition, determining optimum soil moisture, temperature, and seedling age favorable for disease development will create an ideal screening environment for disease resistance.

\section{Materials And Methodology}

\section{Field screening}

One hundred ninety accessions of lentils (details in Supplementary Table S1) were grown in the university experimental field $\left(22.87^{\circ} \mathrm{N}, 88.20^{\circ} \mathrm{E}\right)$ for two consecutive years (2016 and 2017$)$ during the winter season (November to March). The soil at the experimental site was alluvial with $\mathrm{pH}$ 6.8. Before sowing, Sclerotium rolfsii mycelia was added in the experimental plot from the sand-maize meal media at the rate of $100 \mathrm{~g} / \mathrm{m}^{2}$ area. Accessions were evaluated in an augmented block design incorporating three popular cultivars (WBL77, Ranjan, and Asha) as the check of each block. The screening plot was divided into nine blocks containing 25 genotypes (22 accessions and three checks), except the 9th block had 17 genotypes (14 accessions and three checks). Each accession was sown in 3 replications of $2 \mathrm{~m}$ row length spaced $30 \mathrm{~cm}$ apart with the check genotypes. Selected genotypes were tested in two experimental stations having differences in soil pH; one alluvial soil with pH 6.8 (neutral) and another on red and lateritic soil with pH 5.3 (acidic). Based on mortality percentage in-field screening, ten genotypes were 
selected and further evaluated for three consecutive seasons $(2018,2019$, and 2020$)$ in two locations. Plants were grown in $3 \times 4 \mathrm{mt}^{2}$ sick-plots following randomized block design with recommended fertilizer doses. The pure Sclerotium mycelia from the sand-maize meal media mixed the soil appropriately at the rate of $100 \mathrm{~g} / \mathrm{m}^{2}$ area (Supplementary Figure S1) before sowing of seeds. We sown seeds on $15^{\text {th }}$ November each year when the minimum and the maximum daily temperature were $22^{\circ} \mathrm{C}$ and $31^{\circ} \mathrm{C}$. Seedling mortality was recorded in each row and plot 5-30 days after sowing, visible mycelium growth at the collar region. Resistance scoring was based on disease incidence, i.e., mortality percentage (Tarafdar et al. 2018).

\section{Isolation and identification of the pathogen}

Collected plant materials from 10 random places of the field showed considerable mycelium growth at the collar region and typical disease symptoms. The fungus was purely cultured on potato dextrose agar medium (PDA) followed by mass multiplication of fungus in sand-maize meal media (Sand: Maize: Water as 10:1:1) using four days old culture of Sclerotium at $25^{\circ} \mathrm{C}$ (Supplementary Figure S1). Fungal DNA was extracted from the pure culture after the earlier described method (Guha Roy et al., 2009). The internal spacer region (ITS) was amplified using the primer pairs, ITS1 (TCCGTAGGTGAACCTGCGG) and ITS4 (TCCTCCGCTTATTGAT ATGC), as described earlier (Guha Roy et al. 2006). Purified PCR product was Sanger sequenced, and pathogen identified using the BLAST program of NCBI.

\section{Determination of optimum soil moisture, temperature, and seedling age}

Seedlings of a susceptible genotype, L4710, were grown in a plant growth chamber (Phytotron, UK) with temperature and humidity control to determine the optimum moisture and temperature for successful infection by Sclerotium rolfsii. To determine optimum soil moisture, thirty healthy seeds, treated with $2 \%$ sodium hypochlorite followed by repeated washing with sterile water, were sown in closed bottom pots filled with pre-weighed autoclaved pot mixture and considered replication one. We used the watersaturated soil in the first set of pots by adding the required quantity of water. Then, water was added in the second, third, fourth, fifth, and sixth set pots, representing $50 \%, 60 \%, 70 \%, 80 \%$, and $90 \%$ of moisture at field capacity. The soil moisture content of the pot was measured with the moisture meter (LICOR, USA). The moisture lost through evaporation was replenished by adding water periodically. The weight of the pots did not deviate significantly from the initial weight, which ensured the required moisture level throughout the study period. Plants were grown at $25^{\circ} \mathrm{C}$ temperature and $75 \%$ relative humidity with 10 hours light and 14 hours dark. Soil moisture was further calculated from the soil of the collar region on the day of scoring the mortality percentage in each treatment. After determining the optimum moisture level for successful infection, two independent experiments were followed with different temperatures $\left(15^{\circ} \mathrm{C}-35^{\circ} \mathrm{C}\right)$ and artificial inoculations at the various times of seedling's growth (5-40 days after emergence) in pots with previously determined moisture levels to determine the optimum temperature and seedling age. For all experiments, each treatment was present in three replications. Seedling mortality was scored as a percentage of mortality in each experiment. 


\section{Quantification of mycelial load in tolerant and susceptible lines}

The mycelial load was quantified by quantitative real-time PCR following the standard curve with known relative mycelium concentration as described earlier (Ghosh et al., 2019). In brief, fungal DNA has isolated from 12 days old seedlings of a resistant, and susceptible genotype and a Scloritium rolfsii specific ITS region were amplified using the forward 5区(AGTAATGTGAATTGCAGAATCCA)-3》 \&

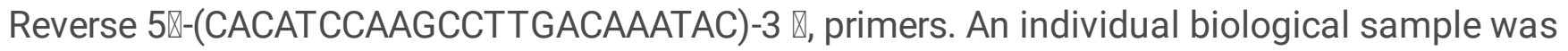
considered as one replication.

\section{Statistical analysis}

ANOVA of the augmented design was followed for calculating the adjusted mean mortality percentage for every nine blocks. The mortality percentage for every 190 genotypes was adjusted, including the three checks accordingly. Variations explained by genotypes, years, and their interaction was calculated from ANOVA of disease reaction data of ten selected genotypes in randomized block design. Non-linear curve fittings were made using GraphPad Prizm 9.0.

\section{Results}

\section{Identification of pathogen}

Infected plant samples from the collar region were collected from the susceptible plants of L4710 (Supplementary Figure S2) and observed under the microscope. The pathogen was identified as Sclerotium rolfsii from the Sclerotium observed. The pathogen was also recognized by sequencing the ITS region and comparing it with a known sequence database using the BLAST program of NCBI, which again confirmed the pathogen as Sclerotium rolfsii. The sequence was submitted to $\mathrm{NCBI}$ and assigned the accession number MN833953. Alignment of the studied sequence with the retrieved chickpea reference sequence (MN610007.1) from NCBI showed 100\% sequence identity (Supplementary Figure 3).

\section{Identification of resistant genotypes}

Screening of one hundred and ninety genotypes for two consecutive years in the field identified fourteen genotypes resistant to collar rot disease. We observed a wide range of resistance reactions ranging from $4 \%-81 \%$. In both years, a continuous frequency distribution of genotypes for percent seedling mortality was observed (Figure 1). Genotypes were grouped based on the mean disease reaction of the two consecutive years (Supplementary Table 1).

\section{Role of soil-moisture temperature and seedling age}

Independent experiments were conducted in a plant growth chamber to find the optimum soil moisture, temperature, and seedling age for successful infection and disease development, by artificially inoculating plants of the susceptible genotype L4710 with purified Sclerotium rolfsii culture. Maximum seedling mortality was observed at $75-80 \%$ soil moisture (Figure 2a). However, there was a sharp 
decrease in mortality below $70 \%$ and above $85 \%$ soil-moisture level. Similarly, seedling mortality reduced when the temperature was below $25^{\circ} \mathrm{C}$ or above $35^{\circ} \mathrm{C}$. (Figure $2 \mathrm{~b}$ ). Interestingly, the $5-20$ days old seedlings mortality did not differ significantly but reduced to less than $10 \%$ after 30 days of emergence (Figure 2c). Thus, the pathogen can cause maximum damage to the 15-20 day old seedlings when the soil moisture and temperature were within the range of $75-80 \%$ and $25-30^{\circ} \mathrm{C}$, respectively.

\section{Validation of tolerant genotypes}

Ten selected genotypes from the previous screening were evaluated in two sick plots in alluvial and lateritic soil. We mixed the soil at both sites with purified $S$. rolfsii culture to ensure sufficient pathogen build-up in the soil. IC2632285, ILL10231, and LL56 showed less than 10\% mortality in alluvial soil with neutral $\mathrm{pH}$ over three consecutive years. On the other hand, Ranjan, a popular cultivar, established more than $25 \%$ mortality in the same field (Figure 3 ). As per ANOVA analysis, genotypes and years explained $80 \%$ and $2 \%$ of the total variances, respectively (Table 1 ). On the other hand, no genotypic differences were observed in lateritic soil with mean mortality of less than $5 \%$.

The mycelial load was secured using real-time PCR from the DNA extracted below the collar region from a resistant (LL56) and susceptible genotype (L4710) to confirm the tolerance reaction. The cycle of thresholds $(\mathrm{Ct})$ value that depends on the initial mycelial load was 32-37 in three biological replicated samples of the resistant genotype LL56, whereas it was 24-26 for the susceptible genotype, L4710 (Figure 4).

\section{Discussion}

The disease was identified by a white cottony appearance of fungal growth on the collar region of plants. The pathogen was identified as $S$. rolfsii by pure culture and the observance of sclerotia under the microscope. Sequencing of the ITS region also confirmed pathogen identification. Our study sequence showed $100 \%$ sequence similarity with a chickpea-collar rot causing Sclerotium retrieved from the NCBI database (Accession no. MN610007). As ITS sequences of all ten isolates were similar, only one sequence was submitted to the NCBI database (MN833953).

Field screening of 190 genotypes revealed various disease reactions (4-81\%) ranging from resistance to highly susceptible responses. Fourteen genotypes were identified as resistant to collar rot disease. However, no genotype was identified as highly resistant. Screening many genotypes for collar rot resistance in chickpea also identified single resistant genotypes only (Chitale et al., 1990). Resistance sources were not limited to broad genetic groups as the identified resistant genotypes belonged to both Mediterranean and Asian groups of germplasm. The present study did not investigate whether resistance to collar rot evolved independently in the Mediterranean and Asian groups or before these groups diverged from a common ancestor.

The role of soil moisture, temperature, and seedling age on the development of collar rot disease was determined by growing plants of susceptible genotype L4710 in a plant growth chamber and practicing 
artificial inoculation. Although soil moisture is an essential factor determining successful infection by soil-borne fungi, we found more than $90 \%$ moisture level was not conducive for Sclerotium growth. Thus, sowing of lentil seeds just before rice harvesting may significantly reduce collar rot infection as soil moisture remains above $90 \%$ in most wet-season rice fields. In the studied area, day-temperature remains $25^{\circ} \mathrm{C}-30^{\circ} \mathrm{C}$ from 15 th to 30 th November with less than $80 \%$ soil moisture in tilled soil, which helps the collar rot pathogen grow profusely. It was previously reported that $70 \%$ moisture and $25-30^{\circ} \mathrm{C}$ temperature favored an outbreak of Sclerotium rolfsii in soybean. One-month-old seedlings showed less mortality as compared with seedlings that were younger (5-20 days). This observation is consistent with the minor outbreak of collar rot in farmer's fields when seedlings are more than one month old. This difference in infection of seedlings of different ages could be due to the more rigid tissue in old seedlings.

Thus, seed sowing just after harvesting rice without any tillage may significantly reduce collar rot infection as the soil moisture remains above $90 \%$ during that time. By the time soil moisture depletes to $80 \%$ or less, seedling age becomes 25 days or more when they are more tolerant to disease. Less mortality was observed in acidic soil, maybe due to the non-preference of acid soil by the pathogen. Collar rot resistance is under polygenic control, like, groundnut (Bera et al. 2016, Cui et al. 2019; Dodia et al. 2019) and alfalfa (Prat et al. 2002), where the genotype factors controlling the trait are higher than the environmental factors observed. The resistance of LL56, as opposed to the susceptible genotype L4710, was confirmed by comparing the mycelial load in twelve-day-old seedlings after artificial inoculation by quantitative real-time PCR. The resistant genotypes identified here will help develop collar rot resistant cultivars and map disease resistance in lentils. Determining optimum soil moisture, temperature, and seedling age favorable for disease development will create an ideal screening environment for disease resistance. Thus this study provides the first step for developing collar rot resistant cultivars and mapping collar rot resistance. This study also indicates an effective strategy for reducing the infection of collar rot in lentils by adjusting sowing timing.

\section{Declarations}

Funding Authors acknowledge ICARDA, for financial support.

Conflicts of interest/Competing interests: The authors declare that they have no known competing financial interests or personal relationships that could have appeared to influence the work reported in this paper.

Availability of data and material Data already provided as supplementary data

Code availability Not applicable

Authors' contributions $A R, C D$ and $S B$ designed the experiment and analyzed the data. AR, CD , DS, DG, SKM, MS, BNP, RN, KT, and PKB performed all experiments along with SB. SB wrote the manuscript.

Ethics approval Not relevant to this manuscript 
Consent for publication Corresponding author behalf of all the authors give the consent for publication of the accepted manuscript.

\section{Acknowledgment:}

Authors acknowledge NBPGR, India, for sharing the germplasm; AR acknowledges the UGC-NFOBCfellowship, Government of India.

\section{References}

Chitale K, Tyagi RNS, Singh RD (1990) Reaction of chickpea cultivars to collar rot disease induced by Sclerotium rolfsii. Ind J Mycol Plant Pathol 20:262-263

Pravi V, Jeeva ML, Archana PV (2014) Rapid and Sensitive Detection of Sclerotium rolfsii Associated with Collar Rot Disease of Amorphophallus paeoniifolius by Species-Specific Polymerase Chain Reaction Assay. Mol Biotechnol 56: 787-794

Johnson N, Johnson CR, Thavarajah P, Kumar S, Thavarajah D (2020) The roles and potential of lentil prebiotic carbohydrates in human and plant health. Plants People Planet 2:310

Bera SK, Kamdar JH, Kasundra SV, Ajay BC (2016) A novel QTL governing resistance to stem rot disease caused by Sclerotium rolfsii in peanut. Australasian PI Patho 45:637-644

Chet I (1975) Ultrastructural basis of sclerotia survival in soil. Microb Ecol 2:194-200

Choukri H, Hejjaoui K, El-Baouchi A, El haddad N, Smouni A, Maalouf F, Thavarajah D, Kumar S (2020) Heat and Drought Stress Impact on Phenology, Grain Yield, and Nutritional Quality of Lentil (Lens culinarisMedikus). Front Nutr 7:596307. doi:10.3389/fnut.2020.59630

Cui R, Clevenger J, Chu Y et al (2020) Quantitative trait loci sequencingderived molecular markers for selection of stem rot resistance in peanut. Crop Sci 60:2008-2018. https://doi.org/10.1002/csc2.20047

Dodia SM, Joshi B, Gangurde SS, Thirumalaisamy PP, Mishra GP, Narandrakumar D, Soni P, Rathnakumar AL, Dobaria JR, Sangh C, Chitikineni A (2019) Genotyping-by-sequencing based genetic mapping reveals large number of epistatic interactions for stem rot resistance in groundnut. Theor App Genet 132(4):1001-1016

Ghosh S, Mazumder M, Mondal B, Mukherjee A, De A, Bose R, Das S, Bhattacharyya S, Basu D (2019) Morphological and SSR marker-based genetic diversity analysis of Indian mustard (Brassica juncea L.) differing in Alternaria brassicicola tolerance. Euphytica 215:1-19

Guha Roy S, Bhattacharyya S, Mukherje SK, Mondal N, Khatua D (2006) Phytophthora melonis associated with fruit and vine rot disease of pointed gourd in India as revealed by RFLP and sequencing of ITS region. J Phytopathology 154:612-615 
Guha Roy S, Bhattacharyya S, Mukherjee SK, Khatua D (2009) Molecular Identification of Phytophthora spp. Affecting some Economically Important Crops in Eastern India through ITS-RFLP and Sequencing of the ITS Region. J Phytopathology 157:666-674

Malhotra N, Panatu S, Singh B, Negi N, Singh D, Singh M, Chandora R (2018) Genetic Resources: Collection, Conservation, Characterization and Maintenance; Elsevier Inc.: Amsterdam, The Netherlands, ISBN 9780128135228

Pratt RG, Rowe DE (2002) Enhanced resistance to Sclerotium rolfsii in populations of alfalfa selected for quantitative resistance to Sclerotinia trifolium. Phytopathology 92(2):204-209

Punja ZK, Jenkins SF, Grogan RG (1984) Effect of volatile compounds, nutrients, and source of sclerotia on eruptive sclerotia germination of Sclerotium rolfsii. Phytopathology 74:1290-1295

Tarafdar A, Rani TS, Chandran USS, Ghosh R, Chobe DR, Sharma M (2018) Exploring Combined Effect of Abiotic (Soil Moisture) and Biotic (Sclerotium rolfsiiSacc.) Stress on Collar Rot Development in Chickpea. Front Plant Sci 9:1154. doi:10.3389/fpls.2018.01154

\section{Tables}

Table 1

ANOVA of mortality percentage from 3 years' replicated data of 10 genotypes in alluvial soil with neutral $\mathrm{pH}$.

\begin{tabular}{|lllll|}
\hline ANOVA table & DF & MS & P value & \% of total variation \\
\hline Genotypes & 9 & 320.1 & $\mathrm{P}<0.0001$ & 79.6 \\
\hline Years & 2 & 39.8 & $\mathrm{P}=0.021$ & 2.2 \\
\hline Interaction & 18 & 4.5 & $\mathrm{P}=0.96$ & 2.2 \\
\hline
\end{tabular}

\section{Figures}




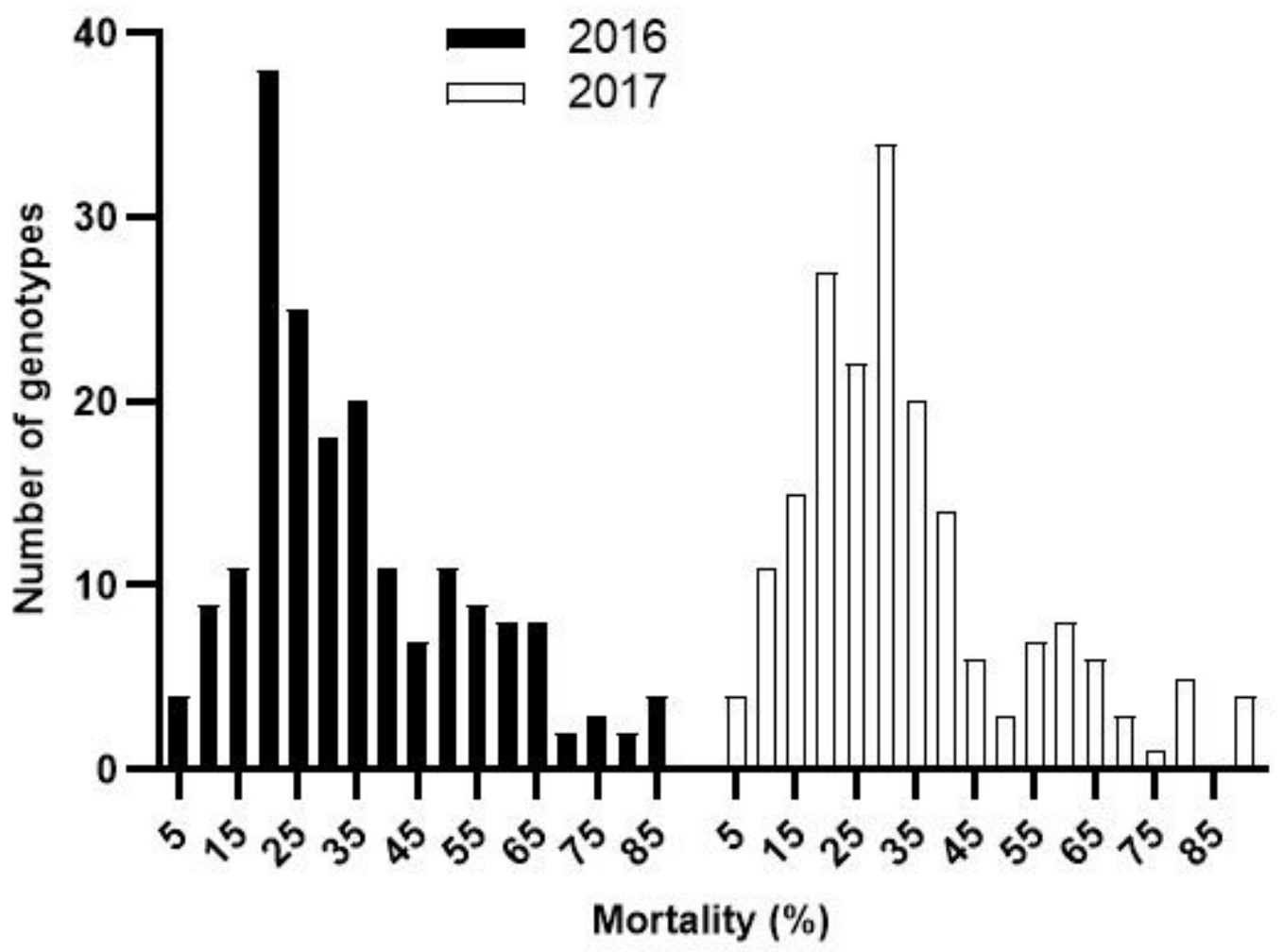

Figure 1

We observed a wide range of resistance reactions ranging from $4 \%-81 \%$. In both years, a continuous frequency distribution of genotypes for percent seedling mortality was observed.
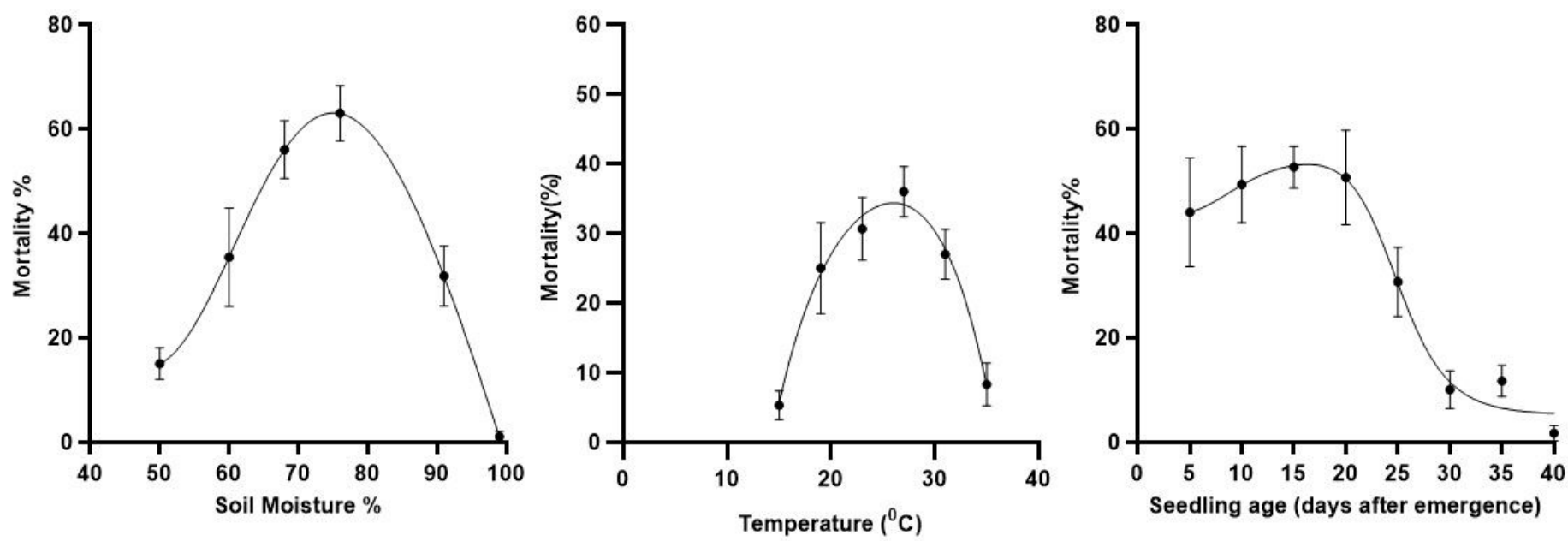

Figure 2

Maximum seedling mortality was observed at $75-80 \%$ soil moisture (Figure $2 a$ ). However, there was a sharp decrease in mortality below $70 \%$ and above $85 \%$ soil-moisture level. Similarly, seedling mortality reduced when the temperature was below $250 \mathrm{C}$ or above $350 \mathrm{C}$. (Figure $2 \mathrm{~b}$ ). Interestingly, the 5-20 days 
old seedlings mortality did not differ significantly but reduced to less than $10 \%$ after 30 days of emergence (Figure 2c).

a

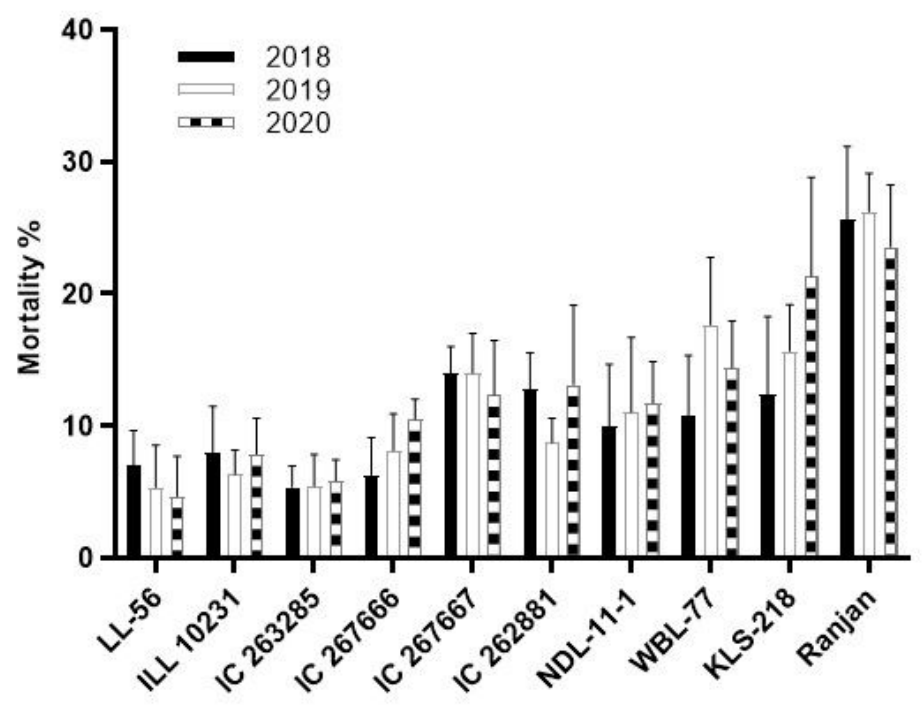

b

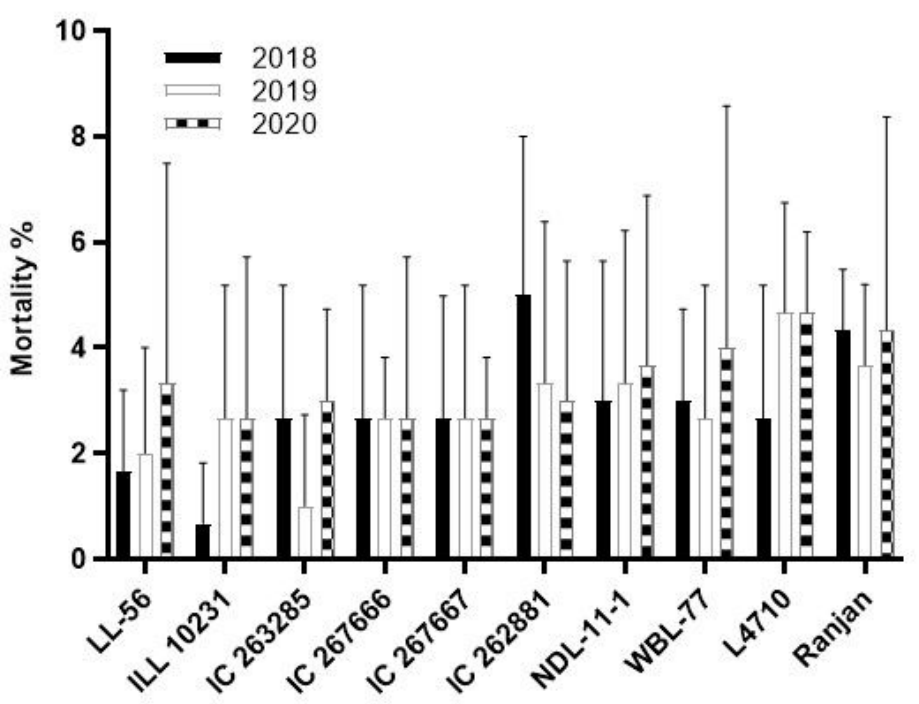

Figure 3

IC2632285, ILL10231, and LL56 showed less than 10\% mortality in alluvial soil with neutral pH over three consecutive years. On the other hand, Ranjan, a popular cultivar, established more than $25 \%$ mortality in the same field (Figure 3). 


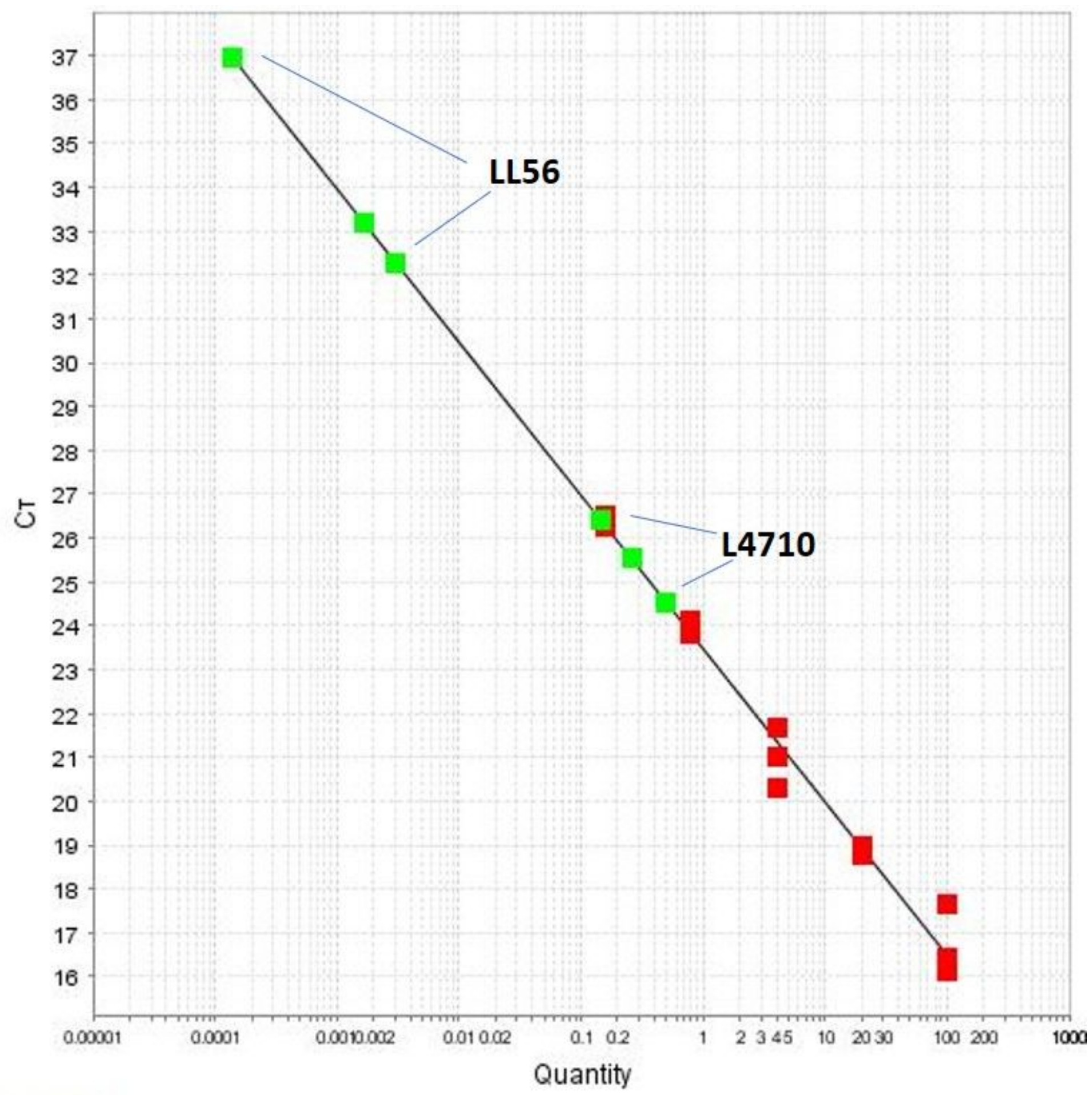

Figure 4

The cycle of thresholds (Ct) value that depends on the initial mycelial load was 32-37 in three biological replicated samples of the resistant genotype LL56, whereas it was 24-26 for the susceptible genotype, L4710 (Figure 4).

\section{Supplementary Files}


This is a list of supplementary files associated with this preprint. Click to download.

- SupplementaryFiguresS1S2S3.docx

- SupplementaryTablesS1S2.docx 